\title{
Allocation of funds and Research Output: The Case of UK Universities*
}

\author{
by \\ Aldo Geuna \\ BETA, Université Louis Pasteur Strasbourg \\ $\&$ \\ MERIT, Maastricht University,
}

Forthcoming in Revue d'Economie Industrielle

Third draft: January 1997

*: Comments and suggestion made by Ed Steinmueller and Katy Wakelin, the supply of the data on the number of publications of UK universities from Diana Hicks, and the research assistance of Myriam Mariani are gratefully acknowledged.

Author's address: BETA, 38 boulevard d'Anvers, 67000 STRASBOURG;

Tel: +33 (0)3 88415209, Fax: +33 (0)3 88613766, e-mail: Geuna@ cournot.u-strasbg.fr 


\begin{abstract}
The paper develops an empirical approach for analysing the relationships between funding and research output. In particular, it focuses on how the changes in the funding structure of multi-disciplinary old British universities have affected their propensity to carry out research of a more applied nature. First, the evolution of the funding structure of UK universities in the period 1989-93 is studied. Then, in order to assess the influence of the funding structure on the research output, the characteristics of 47 multi-disciplinary universities are examined at the start and at the end of the period considered. The analysis developed offers some evidence to support the hypothesis that policies oriented towards a decreasing state financing of university research aimed at a larger university funding from industry may be to the detriment of the scientific research output of these institutions as measured by publications per researcher.
\end{abstract}




\section{Introduction}

Universities, especially in the UK but also in other European countries, are undergoing profound modifications due to budget constraints and changes in policy regarding their purpose in society. These changes are straining the university structure developed after the Second World War. The role of universities is changing from the one of public institutions subsidized by the state into that of suppliers of specific services. Research services offered by the universities are bought by research councils, government departments, charitable foundations, commercial firms and (increasingly) international organizations such as the European Community. On the one hand, the developing market system for university research services has beneficial influences such as reducing financial inefficiency. Nonetheless, on the other hand, given the peculiar features of knowledge production and distribution processes, the market for university research is far from a perfect market, so that the development of a more 'competitive' market does not necessarily imply the production of desirable results from an economic and social point of view (Ziman, 1994).

In this context and in order to understand the possible results of current changes it is useful to assess how a specific group of institutions, the multidisciplinary old British universities, are adapting to recent modifications of funding allocation procedures. The British case has been chosen due to its unique characteristics. The UK is the country of the EU with the most market oriented university system, and consequently with a clearer propensity, or push, towards a more utilitarian, applied, type of research (a summary of the philosophy behind it is the famous statement 'value for money'). The UK system, with its mission oriented policies (selective policies), can be considered an 'attraction pole' or model for emulation for changes in university funding system 
of other European countries. ${ }^{1}$ Therefore, the understanding of the possible consequences of the ongoing changes in the UK universities can give insights which can be used to better direct the evolution of the other European university systems.

Current developments in the university research system suggest changing relationships between the allocation of funds and research output. In this paper a methodology for exploring these relationships is employed to group universities into clusters with small within-cluster variation for discriminating variables --i.e. the institutions in a specific cluster have similar characteristics-and high between-cluster variation --i.e. the universities in the various clusters have different features. This type of analysis is not definitive. There are no clear a priori grounds for the selection of discriminating variables, nor are there clear a priori reasons for selecting the number of clusters (other than purely numerical relationships). Nonetheless, this methodology allows us to identify groups of universities with similar characteristics. The study of the different groups at two points of time, and, in particular, of the movements of institutions among groups allows us to point out the existence of relationships between funding and research output.

The paper is organized as follows. The next section gives a description of the evolution of the funding structure of UK universities. The changes in the different sources of funds in the period 1989-93 are analyzed paying particular attention to the evolution of the receipts from specific services (Section 2.1). In Section 3 the methodology to explore the relationships between allocation of

1 See for example the development of the Dutch research assessment exercise on the model of the first UK Research Assessment Exercise and the current attempts by some German Lander in developing a research assessment exercise 
funds and research output is developed. A cluster analysis for the two period 1989-90 and 1992-93 and the preliminary analysis of the results is presented in Section 3.1. The study of the changes in clusters' membership and some interpretations are offered in Section 3.2. Finally Section 4 presents the conclusions and policy implications.

\section{The evolution of the funding structure of UK universities ${ }^{2}$}

In recent years the UK higher education funding structure has gone through same marked changes. These transformations were the result of government policies that began, in 1980, with the decision to charge fees to foreign students to cover the full costs of their courses. Then, throughout the 80 's, university, polytechnic, and college budgets were restructured in ways that put new pressures (and incentives) on these institutions. A major instrument of reform was a reduction in block grants to Higher Education Institutions (HEIs) which then were offset, less-then-proportionately, by increases in funds from other government sources. The actions were undertaken, on the one hand, to stimulate a process of financial restructuring aimed at reducing costs and, on the other hand, to provide incentives (through mechanisms such as the Research Assessment Exercise and the Technology Foresight) ${ }^{3}$ by which it was hoped that better direction of HEIs research effort would result.

2 This Section draws upon David, Geuna and Steinmueller (1995).

3 While the Research Assessment Exercise is run by the Funding Councils with the aim of a better allocation of research funds to universities, the Technology Foresight, run by the Office of Science and Technology, tries to pull scientific research more towards "the needs of the nation". 
The turning point in the process of change of the funding system was, however, the Education Reform Act of 1988. This Act created two new funding agencies, the Universities Funding Council (UFC) and the Polytechnics and Colleges Funding Council (PCFC), but most importantly it modified the 'logic' of higher education funding. The two agencies were created to act as buyers of academic services. The role of universities, polytechnics and colleges was suddenly transformed, from the one of public institutions subsidized by the state into that of private suppliers of specific services --i.e. teaching and research. This change implied the creation of a new market for HEIs services. HEIs had to learn the new rules of the game, such as bidding for students and interacting with other potential buyers of their services such as industry, or the European Commission. Furthermore they had to adapt their management structure and allocation of funds to the new external situation. ${ }^{4}$

The latest step of this revolution has been the merging of UFC and PCFC into a single Higher Education Funding Council (HEFC) with separate agencies for England, Scotland and Wales in 1993. In addition, 39 Polytechnics and Colleges have been granted university status. This new situation is also the result of the White Paper of May 1991 Higher Education. A New Framework. The report drew the outline for the new structure of the higher education sector in the UK. Of particular relevance for the funding system are the following. First, it has favoured competition for research funds among all the HEIs, which now share a common identity as universities. Second, it endorsed and reinforced the dual support approach. Universities should receive public funds for research

\footnotetext{
${ }^{4}$ For an exhaustive analysis of these changes see G. Williams (1992).
} 
from both the national HEFC and from the Research Councils ${ }^{5}$ for specific projects. Third, together with competition among institutions and the dual system, selectivity on the basis of assessment of research quality and the subdivision of the block grant in teaching and research are the principles that inform the new structure for public funding.

Finally, in May 1993, as a demonstration of the Government 's concern for the science and technology situation, a new White Paper (the "Waldegrave Report") on science and technology, Realising our Potential - A Strategy for Science, Engineering and Technology, was published. ${ }^{6}$ Rather than just being another proposal for further changes, it offered an evaluation of what had happened in the preceding years, and a re-thinking of the system of science, engineering and technology in general. Central to the Waldegrave Report is an examination of the research councils' operations. In addition to the existing five, three new research councils were proposed in the report. From 1994 there are eight active research councils, namely the Natural Environment Research Council (NERC), the Medical Research Council (MRC), the Economic and Social Research Council (ESRC), the Agricultural and Food Research Council (AFRC), the Science and Engineering Research Council (SERC), as well as the new Engineering and Physical Science Research Council (EPSRC), the Biotechnology and Biological Sciences Research Council (BBSRC), and the Particle Physics and Astronomy Research Council (PPARC). The Office of Science and Technology has responsibility for all the Research Councils and also for the LINK programme, "a cross-Government initiative which aims to bridge

\footnotetext{
5 Contract overheads have been increased to $40 \%$ so that the Research Councils have to meet all the costs of their projects. Academic salaries and premises continue to be met from institutions' general funds.
}

6 For a critical analysis of the White Paper 1993 see Webster (1994). 
the gap between the science and engineering base and industry for the benefit of the United Kingdom economy" (White Paper, 1993, p. 35).

\subsection{The aggregate situation}

Due to the relevance of the Education Reform Act, and the fact that data are only available from 1989-1990, we shall focus our analysis on the period between 1989-90 and 1992-93. Furthermore, we decided to take into account only the "old" universities because of their distinct research orientation. Indeed, polytechnics and colleges receive much less research funding; in 1989-90 the levels were $£ 1,620$ million for the old universities and $£ 70$ million for polytechnics and colleges (White Paper 1991, pp. 16). ${ }^{7}$

For the four years considered the Universities' Statistical Record provides an annual report on university funding. All the old universities are covered in this survey. The university funding (income) is broken down in detail by income source. At the most aggregate level the break-down is between general and specific incomes. The former represent the incomes attributed to teaching and to the part of research not covered by specific sources. The main part of it is due to the HEFC grant (Exchequer Grants) and to tuition fees (Fees). Specific incomes consist of the funds gathered by academic departments or academic services for the supply of specific services to outside parties. Among these services, research grants and contracts are the most important item and the following are the largest buyers of university research: Research Council,

\footnotetext{
However, with the new system of funding, ex-polytechnics and colleges are starting to compete more and more for Research Council funding, and they are therefore becoming more involved in research.
} 
Government Bodies, UK - based Charitable Bodies, UK Industry and the European Commission.

Table 1: Relative share of university incomes

\begin{tabular}{|l|c|c|c|c|c|c|c||}
\hline \hline Year & $\begin{array}{c}\text { Exch. } \\
\text { Grants }\end{array}$ & Fees & $\begin{array}{c}\text { Total } \\
\text { Specific }\end{array}$ & $\begin{array}{c}\text { Research } \\
\text { Councils }\end{array}$ & $\begin{array}{c}\text { Govern. } \\
\text { Bodies }\end{array}$ & $\begin{array}{c}\text { UK } \\
\text { Industry }\end{array}$ & EC \\
\hline $\mathbf{1 9 8 9 - 9 0}$ & $48.4 \%$ & $13.8 \%$ & $23.1 \%$ & $6.5 \%$ & $3.0 \%$ & $2.6 \%$ & $1.1 \%$ \\
\hline $\mathbf{1 9 9 0 - 9 1}$ & $39.8 \%$ & $20.7 \%$ & $24.2 \%$ & $6.4 \%$ & $3.3 \%$ & $2.6 \%$ & $1.3 \%$ \\
\hline $\mathbf{1 9 9 1 - 9 2}$ & $35.5 \%$ & $25.0 \%$ & $23.9 \%$ & $6.0 \%$ & $3.1 \%$ & $2.5 \%$ & $1.6 \%$ \\
\hline $\mathbf{1 9 9 2 - 9 3}$ & $33.3 \%$ & $25.3 \%$ & $25.1 \%$ & $7.1 \%$ & $3.1 \%$ & $2.3 \%$ & $1.9 \%$ \\
\hline \hline
\end{tabular}

Source: elaboration of Universities' Statistical Record data.

Table 1 shows the evolution of the relative share of the sources of funds in which we are interested. The most striking trend is the decrease of more then 15 points of the Exchequer Grants' share in university funding (from $48.4 \%$ to $33.3 \%$ of the total). This is the result of both the policy of funding a higher share of university research directly through specified projects, and the decision to link part of teaching money to the number of students, via the increase in fees. ${ }^{8}$ In addition, the share of Fees grew by 11.5 points, raising the share of this funding component to $25.3 \%$. There are two main reasons for this increase. First, the Government sought an incentive for enlarging the number of students admitted to the university. Thus, to spur on universities to accept more students they increased the money given to the institution for each admitted student. Second, this policy was successful in the sense that the number of students

\footnotetext{
8 The share of self-supporting home fees, payed by UK residents or by residents abroad who are entitled by special circumstances to pay home fees (EC students), ranged from 2\% to $4 \%$ in these four years. In short, fees are principally paid by the UK Government.
} 
admitted to higher education markedly increased during the period, raising the total funds paid through this source.

The share of Specific Incomes grew by only 2 points. Consequently, part of the university research that previously was covered by the Exchequer Grants did not find direct support through specific projects. In particular, the Research Councils' share of funds, after a slight decrease over two years, increased in the last year. This is mainly due to the new regulation that states that from 1992-93 the Research Council "will become responsible for meeting all the costs of the projects, except for academic salaries and premises, which will continue to be met from institutions' general funds" (White Paper, 1991, p.17). ${ }^{9}$ The result is that part of the costs associated with the conduct of research facilities, like libraries, were then paid for by the research councils. The share of funds from UK industry, contrary to the expectations of the government, decreased over the period. This may also be due to the recession period, nonetheless it points to the fact that, at least in the period analyzed, industry funds did not counterbalance decreasing government support at the aggregate level. Finally, the EU funding share, although very low, constantly increased almost doubling its value over the period.

Table 2 presents the annual growth rate of the various sources of funds expressed in constant 1986 prices. ${ }^{10}$ First, the decrease in the real value of Exchequer Grants, which started during the 80's is moderating. Indeed, in 199293 there was a nominal (without taking into account inflation) increase. Second,

9 In particular, research grants and contracts income from the Research Council increased from $£ 288$ million to $£ 382$ million, due mainly to the transfer of $£ 87$ million from the Funding Council to the Science Vote.

10 The university cost deflator has been used as the index. 
the Research Council component after two years of decline realized an increase of $26.5 \%$. However, when we compute the real value of the flow of money from the Funding Council (see note 9) we obtain a fall of 2.3 points. Therefore, it appears that even over the recent past the two most important sources of government funding have shown negative trends. Only in the last year, after the policy decision of increasing the overheads for the contracts funded by the Research Councils, does it seem possible to identify the impact of the government strategy oriented towards an increase of specific incomes ${ }^{11}$ and not simply directed at cutting both general and specific incomes. Third, UK industry funding receipts, after a neglectable rise in real terms during 198990/1990-91, show increasingly negative growth rates. Fourth, EU funding receipts have risen throughout the period, whereas the positive growth of university income from Fees has been slowing down. Fifth, and finally, after more or less no changes in real terms during 1989-90/1990-91, Total Recurrent incomes has shown a positive growth rate during the two following periods.

Table 2: Annual growth rate of university incomes in constant price 1986, by source

\begin{tabular}{||l|c|c|c|c|c|c|c|c||}
\hline Year & Total & $\begin{array}{c}\text { Exch. } \\
\text { Grant }\end{array}$ & Fees & $\begin{array}{c}\text { Total } \\
\text { Specific }\end{array}$ & $\begin{array}{c}\text { Research } \\
\text { Councils }\end{array}$ & $\begin{array}{c}\text { Govern. } \\
\text { Bodies }\end{array}$ & $\begin{array}{c}\text { UK } \\
\text { Industry }\end{array}$ & EC \\
\hline $89 / 90-90 / 91$ & $0.0 \%$ & $-17.7 \%$ & $49.7 \%$ & $4.7 \%$ & $-1.6 \%$ & $11.0 \%$ & $0.4 \%$ & $19.1 \%$ \\
\hline $90 / 91-91 / 92$ & $2.9 \%$ & $-8.4 \%$ & $24.2 \%$ & $1.8 \%$ & $-4.8 \%$ & $-4.6 \%$ & $-1.5 \%$ & $21.6 \%$ \\
\hline $91 / 92-92 / 93$ & $5.9 \%$ & $-0.6 \%$ & $7.2 \%$ & $11.2 \%$ & $26.4 \%$ & $6.1 \%$ & $-4.2 \%$ & $26.4 \%$ \\
\hline
\end{tabular}

Source: elaboration of Universities' Statistical Record data

\footnotetext{
11 To favour specific incomes is a way to create incentives for the university in the model of competitive market for university research that the government is pursuing.
} 
In summary, these changes have led to offsetting impacts. On the one hand, taking into account the differences in the relative share of funds for exchequer grant and fees, ${ }^{12}$ and the fact that student enrolment has grown in the three periods by $5.0 \%, 9.1 \%$, and $8.6 \%$ respectively, the increase of receipts in real term from tuition fees has balanced the decrease in the income from the exchequer grant for the teaching side.$^{13}$ On the other hand, the growth of specific incomes has not been sufficient to cover the diminishing of general research funds.

To study the impact on university research output of the changes described above a more disaggregated approach has to be used. In the next section the relationships among scientific research output, dimension and funding structure will be analyzed at the institutional level.

\section{Allocation of funds and research output}

In order to investigate the relationships among scientific research output, dimension and funding structure only 'scientific' faculties (natural sciences, engineering sciences, medical sciences and agricultural sciences) have been considered. Social sciences and humanities are not included in the analyzed sample of universities. In the period considered there were 72 old universities

\footnotetext{
12 For example in 1989-90 the receipts from the exchequer grant were about 3.5 times larger than those from fees.

13 In the last period the nominal increase of income from fees is sufficient to balance the increase in the number of students.
} 
in the UK, ${ }^{14}$ of these 5 did not have scientific faculties. Twenty universities granted a Ph.D. degree in only one or two scientific fields. To reduce the variance in the sample and in order to compare similar institutions, only the institutions that granted a Ph.D. degree in at least three scientific fields have been included in the analysis. For each of the 47 universities considered, the following data have been gathered: ${ }^{15}$

NEWOLD: $\quad$ The founding year of the institution.

NRES:

The number of academic staff in the 'scientific' faculties: 1989-90, 1992-93. ${ }^{16}$

PUBS: $\quad$ Number of papers published by a scholar associated to a specific institution: $1990,1993 .{ }^{17}$

RATIO: $\quad$ The ratio between the number of publications and the number of researchers (PUBS/NRES).

RETOT: $\quad$ The share of research grant and contract receipts in total recurrent income: 1989-90, 1992-93

INDRE: $\quad$ The share of UK industry receipts in the total amount of funds from research grants and contracts: 1989-90, 1992-93.

14 Due to their peculiar characteristics the Senate Institutes \& Central University of London University and the University Central Registry of the University of Wales are excluded from the analysis. Manchester University and UMIST have been considered as one institution. Finally, London University is not considered as a single institution and its 22 component colleges are accounted.

15 Data sources are given in Appendix A.

${ }^{16}$ The number of researchers includes the total of full-time academic staff plus, when present, $50 \%$ of part-time academic staff.

17 For the methodology used in gathering the data see Katz et al. (1995). 
The first variable describes the institution in terms of historical development. The number of researchers variable is a measure of input to research; while the number of publications is an indicator of the scientific output dimension. The ratio between the number of publications and the number of researchers is used as a proxy for the scientific research productivity of the university. ${ }^{18}$ The share of research grant and contract receipts to the university's total recurrent income is used as a proxy for the research orientation of the institution. Finally, the share of UK industry receipts in the total amount of funds from research grants and contracts can be interpreted as a proxy for the propensity to carry out research of a more applied nature.

The representation of the data according to the analyzed characteristics of the universities allows us to highlight the existence of relationships among scientific research output, dimension and funding structure. Moreover, indications of the impact of the changes occurring in the UK university system during the period 1989-90/1992-93 may be extracted by comparing the data at the start and at the end of the period considered.

\subsection{Cluster analysis}

In order to analyze any possible grouping of the institutions according to their characteristics a cluster analysis is implemented. More exactly, first

\footnotetext{
18 The sociology of science, and more recently, empirical studies in the New Economics of Science have made use of bibliometric analysis. In particular, the idea behind paper or citation counts is that they can be used as an indicator of the underlying "quality" of the researcher. Consequently is possible to depict the research "quality" of the university as the ratio between the publications realized in one year and the number of researchers attached to that institution.
} 
principal components are extracted from the original four variables (NRES, RATIO, INDRE, RETOT), then a hierarchical cluster analysis is performed on the principal components. ${ }^{19}$ To define clusters which have small within variation and high between variation the same methodology is used for the 47 universities both in 1989-90 and in 1992-93. For simplicity, only the figures that refer to the period 1989-90 are presented in the following description of the methodology.

Table 3: Rotated loading matrix

\begin{tabular}{||l|c|c|c||}
\hline \hline Variables & $\begin{array}{c}\text { First Principal } \\
\text { Component }\end{array}$ & $\begin{array}{c}\text { Second Principal } \\
\text { Component }\end{array}$ & $\begin{array}{c}\text { Third Principal } \\
\text { Component }\end{array}$ \\
\hline INDRE90 & -0.10525 & 0.98633 & -0.06006 \\
\hline RATIO90 & 0.21735 & -0.06591 & 0.97099 \\
\hline RETOT90 & 0.87844 & 0.03923 & 0.25805 \\
\hline NRES90 & 0.88620 & -0.22842 & 0.09530 \\
\hline
\end{tabular}

The first step consists in extracting the principal components from the original data. Given that $94 \%$ of the total variance is explained by the first three principal components (the first two account for only 74\%) the four original variables can be reduced to three. The loadings (correlations) of the four variables with the three principal components are presented in Table $3 .^{20}$ The first principal component combines the number of academic staff in the scientific faculties and the share of research grant and contracts receipts in the total recurrent income, it can be defined as a proxy for the scientific research size of

${ }^{19}$ A similar methodology has been used in Geuna (1997).

20 In Table 3 the principal component loadings after a Varimax rotation are presented. The Varimax method attempts to minimize the number of variables that have high loading on a principal component. This orthogonal rotation does not effect the goodness of fit of a principal component solution, the total variance explained does not change. 
the university. The second principal component has a high loading only for the share of UK industry receipts, thus it can be interpreted as an index of the propensity to carry out research of a more applied nature. Finally, the only important loading of the third principal component is related to the ratio between the number of publications and the number of scientific researchers, it can be defined as a proxy for the scientific research productivity of the institution.

To investigate the possible clusters within the three new variables a hierarchical cluster analysis is used. Ward's minimum variance method, that combines clusters with the smallest increase in the overall sum of the squared within-cluster distances, has been chosen due to its propensity of joining clusters with a small number of observations. One characteristic of the hierarchical cluster analysis is that the number of clusters is not fixed. A Scheffé test with a significance level of 0.05 has been used to determine the number of cluster that should be analyzed. For each variable, the test makes a comparison of the mean of the various clusters. The best representation of the data is given by the grouping into three clusters. This solution has been also verified with a nonparametric Kruskal-Wallis Test. The hypothesis that the three clusters come from populations having the same distribution is rejected.

\section{Grouping in 1989-90}

In the first period three main clusters are identified. ${ }^{21}$ Cluster II is composed by the largest number of institutions (42.6\%\%), Clusters I and Cluster II include a smaller number of universities (31.9\% and $25.5 \%$ respectively). What are the characteristics of these clusters?

\footnotetext{
21 See Appendix B for the list of the universities.
} 
The first cluster is composed by institutions with a mean of 346 researchers which have published a mean of 173 publications; the mean scientific research productivity of the institution in terms of publication per researcher is 0.51 . The average research orientation is 0.13 , and the mean propensity to carry out applied research is 0.20 . The institutions which are members of the second cluster are generally of larger dimension (mean number of researchers of 479) and tend to publish more (mean number of publications of 350). Their mean scientific research productivity is higher than the previous cluster (mean publications per researcher of 0.75). While the research orientation is higher, the average share of industrial funds tend to be lower. Finally, Cluster III is composed by large universities (mean number of researcher of 1206) with high publication output (mean number of publications of 1001) and high scientific research productivity (mean publications per researcher of 0,82). As for the previous cluster, while the research orientation increases (mean research grant and contract funding share of 0.23) the applied research propensity tend to be lower (mean industry funding of 0.11 ).

Table 4: Cluster composition in 1989-90, mean values for the five variables

\begin{tabular}{||l|c|c|c||}
\hline Variables* & Cluster I & Cluster II & Cluster III \\
\hline No. of researchers 90 & 346 & 479 & 1206 \\
\hline Publications 90 & 173 & 350 & 1001 \\
\hline Publications per researcher 90 & 0.51 & 0.75 & 0.82 \\
\hline Research funding share 90 & 0.13 & 0.16 & 0.23 \\
\hline Ind ustry funding share 90 & 0.20 & 0.15 & 0.11 \\
\hline No. of Universities & 15 & 20 & 12 \\
\hline
\end{tabular}

*: For each variable the nonparametric Kruskal-Wallis Test has been run. The hypothesis that the three clusters come from populations having the same distribution is rejected. 
The variable NEWOLD is used to study the historical composition of the clusters. Half of the post-war universities are in Cluster I; $60 \%$ of the institutions in the cluster have been founded in this century. The second cluster is polarized towards old institutions, $60 \%$ of the universities in this cluster were created before the twentieth century. In the third cluster the share of institutions founded before the end of the nineteenth century rises to $83.3 \%$; none of the post-war universities are in this cluster.

The analysis of the data according to the considered characteristics enables us to define three groups of institutions with small within-cluster variation for discriminating variables --i.e. the institutions in a specific cluster have similar characteristics-- and high between-cluster variation --i.e. the universities in the various clusters have different features. The first cluster is composed mainly by twentieth century universities with small scientific faculties that tend to have low scientific research productivity and have the highest propensity to carry out applied research. The institutions in Cluster II are mostly nineteenth century universities, they tend to have scientific faculties of bigger dimensions with larger scientific research output and higher research orientation. However, while their mean scientific research productivity is high, their propensity to develop research in collaboration with industry is lower than in the previous cluster. Finally, the third cluster is almost entirely composed of medieval and nineteenth century universities of very large dimensions that have high scientific research productivity and a low applied research propensity.

In 1989-90 the 47 multi-disciplinary UK universities were characterized by a positive relationship among dimension, research orientation and scientific research output, and a negative relationship between these three variables and applied research propensity. On the one hand the institutions of small scientific 
dimension with low scientific research productivity of Cluster I, on average, received only $13 \%$ of their total recurrent incomes from grants and research contracts, but $20 \%$ of these funds were receipts from UK industry. On the other hand, the very large high scientific research productivity universities of Cluster III had $23 \%$ of their total recurrent incomes originating in research grants and contracts, but only $11 \%$ of these were funded by UK industry. Moreover, the institutions in Cluster I were those with the largest share of UK industry receipts in total recurrent income.

The above analysis seems to point to the existence of a divide between a group of universities of smaller scientific dimension, with lower scientific research productivity that tend to have relatively higher relationships with industry, and a group of large institutions with high scientific research productivity that, despite having a relevant research orientation, tend to have a less important interactions with UK industry. Between these extremes a large group of institutions tend to have average values for the variables considered.

\section{Grouping in 1992-93}

Also in 1992-93 the three cluster solution gives the best representation of the data. ${ }^{22}$ The first two clusters have similar dimensions, while the third includes only the Universities of Cambridge and Oxford. What are the characteristics of these clusters?

The institutions in the first cluster tend to be of small dimension (both in the case of the scientific faculties only and in the case of the complete

\footnotetext{
22 See Appendix B for the list of the universities.
} 
university), ${ }^{23}$ with low scientific research productivity. While their research orientation is low the share of UK industry funds tend to be high. The second cluster is composed of universities of larger dimension with larger scientific research output and higher scientific research productivity. Even if they have higher research orientation, they tend to carry out a lower share of applied research. Finally, Cambridge and Oxford, due to their peculiar characteristics (the highest scientific research productivity, extremely high research orientation, low share of UK industry funds, and large dimension and scientific research output) form Cluster III. Contrary to the 1989-90 case the analysis of the historical composition of the clusters does not allow us to highlight any historical polarisation either in Cluster I or in Cluster II. ${ }^{24}$

Table 5: Cluster composition in 1992-93, mean values for the five variables

\begin{tabular}{||l|c|c|c||}
\hline Variables* & Cluster I & Cluster II & Cluster III \\
\hline No. of researchers 93 & 478 & 836 & 1698 \\
\hline Publications 93 & 293 & 667 & 2266 \\
\hline Publications per researcher 93 & 0.60 & 0.84 & 1.33 \\
\hline Research funding share 93 & 0.14 & 0.20 & 0.33 \\
\hline Industry funding share 93 & 0.16 & 0.09 & 0.08 \\
\hline No. of Universities & 24 & 21 & 2 \\
\hline
\end{tabular}

*: For each variable the nonparametric Kruskal-Wallis Test has been run. The hypothesis that the three clusters come from populations having the same distribution is rejected.

In 1992-93 the 47 UK universities considered tended to be characterized by relationships among dimension, research orientation and scientific research

23 When the entire university is considered the number of researchers and students, and the total recurrent income have low mean values.

${ }^{24}$ Obviously Cluster III includes only medieval universities! 
output similar to the ones of four years before. Also, the negative relation between these three variables and the applied research propensity is confirmed. On the one hand the universities of Cluster I received, on average, 14\% of their total recurrent incomes from grants and research contracts, and $16 \%$ of these funds were receipts from UK industry, while on the other hand the institutions of Cluster II had $20 \%$ of their total recurrent incomes originated by research grants and contracts, but only $9 \%$ were financed by UK industry.

Going from 1989-90 to 1992-93 we witness a movement of institutions among the clusters. The intermediate Cluster II of 1989-90 disappears. Nine universities have moved to the lower scientific research productivity cluster, while eleven institutions have been attracted by the cluster on the other extreme. What are the characteristics of these institutions? Did their funding structure change in the time interval considered?

\subsection{Analysis of the changes in clusters' membership}

The representation of the data according to the analyzed characteristics has allowed us to point to the existence of particular relationships among scientific research output, dimension and funding structure. Given the fact that two different cluster structures are present at the start and at the end of the period considered it is possible to study if this modification --the movement of institutions among groups-- is related to changes in the funding structure. 
In the following section we shall focus on the twenty universities that were members of Cluster II in 1989-9025. Four years later nine institutions were attracted by the first cluster (downgrading) and eleven by the third cluster (upgrading). Did the characteristics of these universities change over the studied time interval? In the first period the downgrading institutions were of larger dimensions, with lower scientific research productivity, but they had a research orientation and a propensity to carry out research of a more applied nature similar to those of the upgrading universities. Compared to four years before, in 1992-93 the eleven upgrading institutions were characterized by an extremely high scientific research productivity, while their applied research propensity was much lower. The nine universities attracted by Cluster I witnessed only minor changes; nonetheless, given the fact that all the other institutions, on average, saw an important decrease of the share of UK industry receipts (in real terms), their roughly unchanged share of UK industry funds indicates a change in their propensity towards a research of a more applied nature. ${ }^{26}$

Going from 1989-90 to 1992-93, on the one hand the eleven upgrading universities increased their scientific research productivity and decreased their applied research propensity, while, on the other hand, the nine downgrading universities had a nearly unchanged scientific research productivity keeping a high propensity towards a research of a more applied nature.

25 The following analysis is based on the mean values of the two groups of institutions considered. For each variable used in the discussion the nonparametric Kruskal-Wallis Test has been run. The hypothesis that the two groups come from population having the same distribution is rejected.

${ }^{26}$ In 1992-93 the nine downgrading institutions had an applied research propensity similar to the one of the universities originally in Cluster I. 
Table 6 shows the mean real changes in the receipts from Exchequer Grant, Research Council, UK Industry and in the Industry funding share ${ }^{27}$ for the two groups of institutions. Both groups of universities suffered important cuts at the Exchequer Grant receipts, and witnessed an increase of the funds from the Research Council. However, while the reduction in the Exchequer Grant has been more relevant for the downgrading institutions, the raise of Research Council receipts has been more important for the upgrading universities. The funds from UK industry followed opposite trends for the two groups. On the one hand the downgrading institutions succeeded in attracting a larger amount of funds from UK industry, and the share of these receipts in their total amount of funds from research grants and contracts stayed approximately constant. On the other hand, both the total amount and the share of UK industry fell dramatically for the upgrading universities.

Table 6: Real changes in university receipts, mean values for selected funding sources

\begin{tabular}{||l|c|c||}
\hline & Downgrading & Upgrading \\
\hline Exchequer Grant & -0.28 & -0.23 \\
\hline Research Council & 0.16 & 0.34 \\
\hline UK Industry & 0.15 & -0.25 \\
\hline Industry funding share & -0.03 & -0.39 \\
\hline
\end{tabular}

In the period considered the nine downgrading universities suffered extremely large cuts to their general state support, consequently they tried to

27 Also the changes of other sources of funds have been studied, however only for the four variables discussed in the text the nonparametric Kruskal-Wallis Test allowed us to reject the hypothesis that the two groups come from populations having the same distribution. Nonetheless, the changes in the other considered sources were coherent with the interpretation presented. 
increase the incomes from specific sources, and in particular, they succeeded in attracting an increasing number of contracts from UK industry. The eleven upgrading institutions saw their Exchequer Grant receipts decreasing, although less than in the case of the other group. They too had to relay more on specific sources of funds, but instead of orientating their research effort more towards the need of UK industry, such as the downgrading universities, they managed to obtain a larger amount of funds from research contracts and grants of the Research Council.

Are the characteristics of the universities member of the two groups related to the changes in their funding structure? A clear answer to this questions is not possible with the current level of analysis. Nonetheless, is important to notice how the negative relationship between the applied research propensity (share of UK industry funds) and the scientific research productivity highlighted in the two period analysis is confirmed also when the changes are studied. The downgrading universities that suffered extremely large cuts in their Exchequer Grant receipts, and partially substituted these funds with industry money, are also the ones that tend to have a decreasing scientific research productivity. ${ }^{28}$ The upgrading institutions that partially counterbalanced the cuts in the Exchequer Grant with an increase of receipts from the Research Council, reducing at the same time their interactions with $\mathrm{UK}$ industries, are the one that showed an important raise in their scientific research productivity.

The findings both at the static level --the universities of smaller scientific dimension, with lower scientific research productivity tended to have a higher

\footnotetext{
28 A basic feature of scientific production is the increase in the number of publications, thus a stationary trend means in practice a decrease in the productivity. See Katz et al. (1995) for a detailed analysis of publishing patterns in the UK.
} 
propensity to develop research of a more applied nature-- and at the dynamic level --relevant cuts in the general state support, not counterbalanced by an increase of state specific funds tended to push universities to relay more on industry funds, and it lead to a reduction in their scientific productivity-- offer some evidence of the existence of a trade off between scientific research productivity (in terms of publications per researcher) and the intensity in the collaboration with industry. In a context of reducing state support the increase in commercializable research in universities, to possibly foster state economic development, may result in a shift away from basic research (to the extent that this is measured by publications per researcher) that will cause a lower rate of technological innovation in the long term (Feller, 1990). ${ }^{29}$ This shift is more relevant for those universities with tighter budgets more dependent on the general funds that, in a period of reducing state support, are constrained to involve a large amount of their scarce resources for research in contracts with industries.

The subdivision in two groups of the UK universities, one of lower scientific research productivity more involved in applied research oriented to the commercialization of research, and the other of higher scientific research productivity with relatively lower interactions with industry may seems, at least to some observer, an optimal outcome. Nonetheless, if the budget cuts and the push towards higher university funding from industry will continue ${ }^{30}$ what is now true for the lower scientific research productivity group may become true for the majority of the universities. Moreover, as pointed out in Faulkner and Senker (1995) and confirmed by the aggregate real decrease of UK industry

\footnotetext{
29 See also Faulkner and Senker (1995).

30 There are proposals to increase the weight given to the collaboration with industry in the Research Assessment Exercise.
} 
receipts showed in Section 2, there are indications that industrialists start to think that contracting to university may cause a diminution of the available stock of basic knowledge that is most useful to their innovation process. In this situation further cuts to the state support will put universities in conditions of unstable funding causing a decrease in the contractual power with industry that may lead the way to the destruction of the norms, incentives and organizational structure of the "open science"31 kind of research typical of the university.

\section{Conclusions}

Governmental and industrial decisions are influencing the evolution of the university system. The modifications involved in this process will affect, for better or for worse, the production and distribution of scientific and technological knowledge. The science and technology policy frameworks of today, that originated in a period of continuously expanding state financing, are of little use in the current context of budget restrictions. Contemporary policy initiatives, to increase the commercializable research in universities with the aim of possibly fostering state economic development, are being taken more on the basis of the laissez-faire philosophy in fashion rather than on the basis of a sound theoretical analysis. In the most influential policy circles it is thought that what has been beneficial for the industrial sector (deregulation and privatization) will also be good for the publicly-funded scientific research. This neglects the peculiarities of knowledge production and distribution processes. With a lack of theoretical guidance, the medium to long term results of governmental and

31 For an analytical history of the emergence of the institutions of "open science" see David (1994); for the role played by norms, incentives and organizational structure in the creation of knowledge see Dasgupta \& David (1987, 1994). 
industrial decisions may be far from desirable from an economic and social point of view, creating a variety of unintended consequences.

This exploratory paper is an attempt to develop an empirical approach for analysing the relationships between funding and research output. In particular, it focuses on how the changes in the funding structure of multi-disciplinary old British universities have affected their propensity to carry out research of a more applied nature. First, the evolution of the funding structure of UK universities in the period 1989-93 is studied. Then, in order to assess the influence of the funding structure on the research output, the characteristics of 47 multidisciplinary universities are examined at the start and at the end of the period considered.

The model of a competitive market for university research pursued by the British government, that originated from a laissez-faire or perfect competition model of how institutions should be made to operate, favours, directly and indirectly, the receipt of incomes from specific services rather than general funds which have been systematically cut. The aggregate analysis of university funding has shown that in the four years considered the real growth of specific incomes has not been sufficient to cover the reductions in general funds. Moreover, of particular importance, and contrary to the alleged increase of university-industry cooperation, is the decrease of UK industry funding receipts. Despite British government programmes to facilitate research collaborations between university and industry, at the aggregate level the share of funds from UK industry declined over the period.

The methodology used to represent the data according to the analyzed characteristics of the 47 universities has allowed us to highlight the existence of 
relationships among scientific research output, dimension and funding structure. The analysis at the static level (at the start and at the end of the period) offers some evidence that universities with smaller scientific faculties and with lower scientific research productivity tended to have a higher propensity to develop research of a more applied nature. Although they had a lower share of receipts from grants and research contracts, the share of these receipts received by the universities from UK industry tended to be high. At the dynamic level (changes between the two periods) we have found some indication that the relevant cuts in the general state support, not counterbalanced by an increase of state specific funds tended to push universities to rely more on industry funds, and it lead to a reduction of their scientific research productivity as measured by publications per researcher.

The analysis developed thus offers some evidence to support the hypothesis that policies oriented towards a decreasing state financing of university research aimed at a larger university funding from industry may be to the detriment of the scientific research output of these institutions as measured by publications per researcher. Further analysis taking into account better indicators of the scientific research output, such as the publications weighted by their impact factor, is need to support this conclusion. Nonetheless, the outcomes of this study point to the existence of a series of problematiques that the current policy approach has avoided. A rethinking and reassessment of the science and technology policy frameworks that take into account the benefits and the drawbacks of the market approach on a medium to long term horizon is needed. In particular, in regard to the university system, the answers to questions such as the following have to become the building blocks for the development of a new policy framework. What are the consequences for research and teaching of a more contract oriented type of university research? What are the economic 
and social returns of a larger industry funding of university research? What share of university incomes should be financed by industry? Are the advantages of scientific agglomeration --i.e. geographical concentration of scientific capabilities, and the localization of the large part of research in a few universities-- offset by the negative externalities imposed on smaller universities which are excluded or marginalized by this process? 


\section{References}

Dasgupta, P. and P.A. David, 1987, Information Disclosure and the Economics of Science and Technology, Chap. 16, in G. Feiwel (ed.), Arrow and the Ascent of Modern Economic Theory, New York University Press, New York.

Dasgupta, P. and P.A. David, 1994, Towards a New Economics of Science, Research Policy, 23/5, September.

David, P.A., 1994, Reputation and Agency in the Historical Emergence of the Institutions of the "Open Science", MERIT's Research Memoranda, No. 2/94006, Maastricht, The Netherlands.

David, P.A., A. Geuna and E. Steinmueller, 1995, Additionality as a Principle of European R\&D Funding, MERIT's Research Memoranda, No. 2/95-012, Maastricht, The Netherlands.

Faulkner, W. and J. Senker, 1995, Knowledge Frontiers. Public Sector Research and Industrial Innovation in Biotechnology, Engineering ceramics, and parallel Computing, Oxford University Press, Oxford.

Feller, I., 1990, Universities as Engines of R\&D-Based Economic Growth: They Think They Can, Research Policy, 19, 335-348.

Geuna, A., 1997, The Internationalisation of European Universities: A Return to Medieval Roots, Minerva A Review of Science, Learning and Policy, forthcoming. 
HMSO, 1993, Realising our potential. A strategy for Science, Engineering and Technology.

HMSO, 1991, Higher Education. A New Framework.

HMSO, 1988, Education Reform Act 1988 Chapter 40, (Reprinted 1989).

Katz, J.S., Hicks, D., Sharp, M., and Ben R. Martin, 1995, The Changing Shape of British Science, STEEP Special Report No 3, SPRU.

Webster, A., 1994, UK Government's White Paper (1993): A Critical Commentary on Measures of Exploitation of Scientific Research, Technology Analysis \& Strategic Management, Vol.6, No. 2, pp. 189-201.

Williams, G., 1992, Changing Patterns of Finance in Higher Education, The Society for Research into Higher Education \& Open University Press, Buckingham.

Ziman, J., 1994, Prometheus Bound. Science in a Dynamic Steady State, Cambridge University Press, Cambridge. 
Appendix A: Data sources

NEWOLD: International Handbook of Universities, International Association of Universities, 1994.

NRES: University Statistics. Volume Three: Finance, Universities' Statistical Record, 1991, 1994.

PUBS: $\quad$ J.S. Katz and D. Hicks, B.E.S.S. Database, SPRU, 1996.

INDRE: University Statistics. Volume Three: Finance, Universities' Statistical Record, 1991, 1994.

RETOT: University Statistics. Volume Three: Finance, Universities' Statistical Record, 1991, 1994. 


\section{Appendix B: List of Universities}

\begin{tabular}{|c|c|c|}
\hline \multirow[t]{2}{*}{ Universities } & \multicolumn{2}{|c|}{ Clusters } \\
\hline & $1989-90$ & $1992-93$ \\
\hline Aston University & I & $\mathrm{I}$ \\
\hline Bath University & $\mathrm{I}$ & $\mathrm{I}$ \\
\hline Bradford University & $\mathrm{I}$ & $\mathrm{I}$ \\
\hline Brunel University & $\mathrm{I}$ & $\mathrm{I}$ \\
\hline Heriot-Watt University & I & $\mathrm{I}$ \\
\hline Hull University & I & $\mathrm{I}$ \\
\hline Kent at Canterbury University & $\mathrm{I}$ & $\mathrm{I}$ \\
\hline Loughborough University of Technology & $\mathrm{I}$ & $\mathrm{I}$ \\
\hline Nottingham University & $\mathrm{I}$ & $\mathrm{I}$ \\
\hline Salford University & $\mathrm{I}$ & $\mathrm{I}$ \\
\hline Stirling University & $\mathrm{I}$ & $\mathrm{I}$ \\
\hline Ulster University & $\mathrm{I}$ & $\mathrm{I}$ \\
\hline Wales University, Swansea & $\mathrm{I}$ & $\mathrm{I}$ \\
\hline $\begin{array}{l}\text { Wales University, Aberystwyth } \\
\text {. }\end{array}$ & $\mathrm{I}$ & $\mathrm{I}$ \\
\hline Warwick University & I & $\mathrm{I}$ \\
\hline Aberdeen University & II & $\mathrm{I}$ \\
\hline Exeter University & II & $\mathrm{I}$ \\
\hline Leeds University & II & $\mathrm{I}$ \\
\hline Newcastle University & II & $\mathrm{I}$ \\
\hline Reading University & II & $\mathrm{I}$ \\
\hline Strathclyde University & II & I \\
\hline Surrey University & II & $\mathrm{I}$ \\
\hline Wales University, Cardiff & II & $\mathrm{I}$ \\
\hline York University & II & $\mathrm{I}$ \\
\hline Belfast Queen's University & II & II \\
\hline Dundee University & II & II \\
\hline Durham University & II & II \\
\hline East Anglia University & II & II \\
\hline Essex University & II & II \\
\hline Keele University & II & II \\
\hline Lancaster University & II & II \\
\hline Leicester University & II & II \\
\hline London University, Queen Mary and Westfield College & II & II \\
\hline Sheffield University & II & II \\
\hline Sussex University & II & II \\
\hline Birmingham University & III & II \\
\hline Bristol University & III & II \\
\hline Edinburgh University & III & II \\
\hline Glasgow University & III & II \\
\hline Liverpool University & III & II \\
\hline London University, Imperial College & III & II \\
\hline London University, King's College & III & II \\
\hline London University, University College & III & II \\
\hline Manchester University & III & II \\
\hline Southampton University & III & II \\
\hline Cambridge University & III & III \\
\hline Oxford University & III & III \\
\hline
\end{tabular}

